\title{
Interactive Creative Problem Solving
}

\author{
STEVEN E. LEBLANC ${ }^{1, *}$ and H. SCOTT FOGLER ${ }^{2}$ \\ 'Department of Chemical Engineering, University of Toledo, Toledo, Ohio 43606, and ${ }^{2}$ Department of \\ Chemical Engineering, University of Michigan, Ann Arbor, Michigan 48109
}

\begin{abstract}
A set creative problem-solving tools for instructional purposes is discussed. The tools include a problem-solving text which presents the heuristic, a set of slides in electronic form that can be used to enhance classroom presentations, and interactive computer modules that reinforce and develop the students' problem-solving skills. (C) 1996 John Wiley $\mathcal{E}$ Sons, Inc.
\end{abstract}

\section{INTRODUCTION}

Information explosion! Expanding knowledge base! Information overload! Technological revolution! Information superhighway! These terms are indicative of an epidemic that affects (and "infects") all of us. The Industrial Revolution took place in the $1800 \mathrm{~s}$. We are now in the midst of an "Information Revolution." A special breed of new engineer will be required to be successful in the future, and the future is now. The development of innovative engineers capable of facing the challenges of the $21 \mathrm{st}$ century is our responsibility as engineering educators. Our graduates will have to contend with, and be able to take advantage of, this rapidly expanding knowledge base if they can hope to be successful in global competition. To meet those challenges, our engineering graduates need to be excellent problem solvers. Effective problem-solving skills are essential to engineering innovation and lifelong learning. Our students must be capable of training and retraining themselves several times over the course of their engineering careers, as old knowledge becomes obsolete and new technology takes its place. Who will

* To whom correspondence should be addressed. Computer Applications in Engineering Education, Vol. 4(1) 35 39 (1996)

(C) 1996 John Wiley \& Sons, Inc. $\quad$ CCC 1061-3773/96/010035-05 be the developers of these new technologies? Innovative engineers with excellent problem-solving skills will undoubtedly be at the forefront of this technology revolution. Innovation and creative problem solving does not just happen. There are skills that need to be developed and honed. To assist in this process, we have developed a number of tools to help students and engineers improve their problem-solving skills.

\section{BACKGROUND}

Over the past 6 years, we have researched the problem-solving techniques used by engineers in industry. Teams of students and faculty visited a number of companies to study problem-solving strategies. We also carried out an extensive survey of new employees, experienced engineers, and managers in industry to collect information on the problem-solving process. As a result of our research, we know that students can develop their creativity and problem-solving skills and become problem solvers. Our research has produced a number of tools that can be used by students and engineers to develop their skills. These tools include

\section{- a textbook entitled Strategies for Creative Problem Solving [1],}




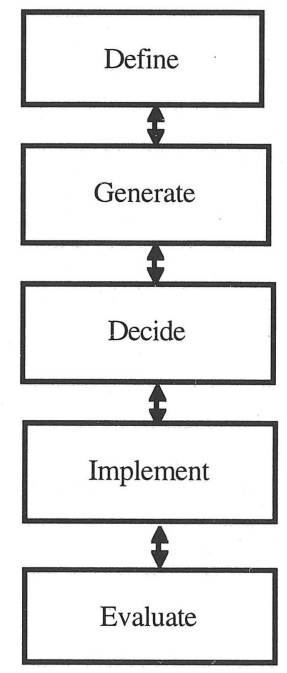

Figure 1 Problem-solving heuristic.

- a set of 150 slides in electronic form to supplement the problem-solving text, and

- a series of interactive computer modules dealing with problem-solving skills.

A brief description of each of these tools follows.

\section{STRATEGIES FOR CREATIVE PROBLEM SOLVING [1]}

This book, published by Prentice Hall in 1995, was the product of a number of years of effort and research into the field of creativity and problem solving. The problem-solving heuristic that serves as the framework for the book is shown in Figure 1. This heuristic, which has its roots in the McMaster Five-Point Strategy [2], was developed after many discussions with practicing engineers and managers in industry. It serves as the basis for solving a wide variety of problems. One of the very useful elements of the heuristic is the problem definition step. To be able to identify the "real problem" as opposed to the "perceived problem" is essential to arriving at a viable solution. In this regard, industry was very helpful in sharing numerous examples of illdefined problems with us. These were problems that were incorrectly defined from the outset, causing the engineers great difficulty in obtaining a workable solution. We approached the companies with a classic example of an ill-defined problem and asked them to contribute examples from their own experience. They responded with a number of problems that we included in the book. The ill-defined problem that we shared with them involved NASA's desire in the early 1960 s to develop a material that would withstand the temperatures of reentry. By the early 1970s, such a material still had not been found, yet we had sent astronauts to the moon and back. How was the problem solved? The real problem was to find a way to protect the astronauts during reentry, not the development of a high-temperature material. The well-known solution to this problem was ablative cooling using a sacrificial material that dissipated the heat of reentry. Thus, by recognizing the real problem-protect the astronauts - as opposed to the perceived problem-develop a high temperature material - a solution became possible.

The book shares numerous real-life examples of problems and solutions interwoven with the heuristic and specific techniques to improve the student's problem-solving abilities. To improve the instructor's ability to deliver this material to the students, we have developed several computer tools that can enhance the learning process by making the material come alive and be more exciting.

\section{ELECTRONIC SLIDES}

We have developed over 150 slides using Microsoft PowerPoint ${ }^{\circledR}$. The slides are available in electronic form and can be displayed interactively in the classroom using a PC or Macintosh and a video display panel or projection system. Multimedia classrooms are becoming increasingly prevalent on campuses, so this should prove to be a popular option for students as well as faculty. Examples of two of the slides are shown in Figures 2 and 3.

The slides may be viewed using the MS PowerPoint ${ }^{\circledR}$ Viewer application, which may be freely distributed for viewing purposes, so the user need not be an owner of the PowerPoint ${ }^{\circledR}$ application. The slides cannot be edited using the Viewer; thus, having PowerPoint ${ }^{\circledR}$ is advantageous if the instructor wishes to customize the presentation.

\section{INTERACTIVE COMPUTER MODULES}

Interactive computer modules were developed for use with the text, because the students' learning is enhanced if they can be an active participant in the process. The modules give them an opportunity to be actively involved in the learning. A series of 11 interactive computer modules were developed by undergraduate chemical engineering students at the University of Michigan during the summers of 1993 and 1994. The software development teams were 


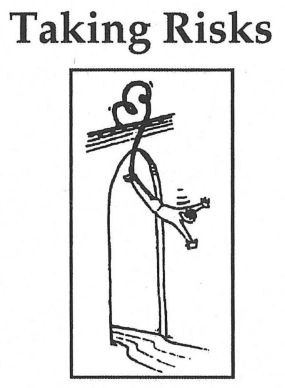

Some simple things you can do that will make you become more comfortable with risk-taking:

$$
\begin{aligned}
& \text { - Challenge established patterns of doing business in } \\
& \text { your organization. } \\
& \text { - Try a new sport, (e.g., skydiving). } \\
& \text { - Join a thespian group. } \\
& \text { - Volunteer to be the organizer of a group activity. } \\
& \text { - Volunteer to speak at a conference/meeting. } \\
& \text { - Buy an expensive piece of clothing a size too small so } \\
& \text { you will have to lose weight to wear it. } \\
& \text { - Sing at a Karaoke bar. } \\
& \text { - Try to repair plumbing by yourself. }
\end{aligned}
$$

Figure 2 Example slide (Taking Risks).

managed by Professor Susan Montgomery. Funding for the project and distribution of the modules was provided by the National Science Foundation (Grant USE-9254345), the CACHE Corporation, and the University of Michigan College of Engineering.

Using the modules allows the students to review and demonstrate mastery of the material at their own pace and provides immediate feedback to their responses [3]. The modules have been designed and tested to best address the issues that ensure success in interactive computer learning:

- ease of use

- maintaining focus on the concepts

- promoting learning

\section{Step 1: Collect and Analyze Information} and Data

Five to six weeks in the laboratory can save you an hour in the library.

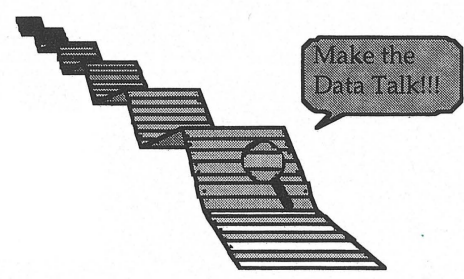

Figure 3 Example slide (Collecting and Analyzing Data).

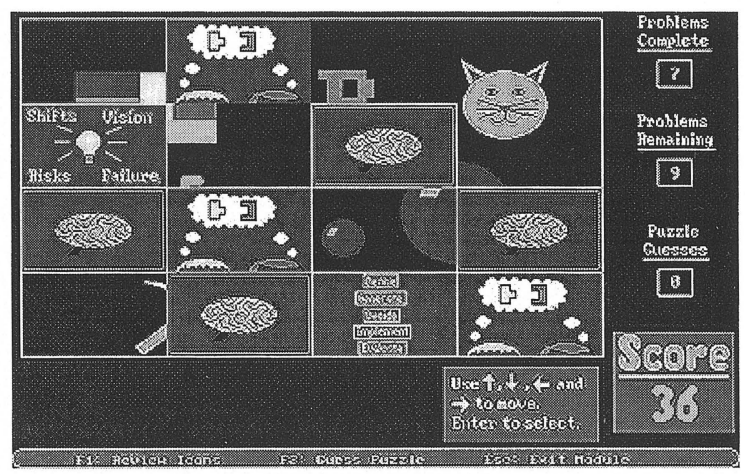

Figure 4 Concentration module.

- individual guidance.

Additional features included in some of the modules include introductions to new technologies using graphic animations and entertaining motivators, which have been shown to increase the students' interest and motivation for the module content $[4,5]$.

The modules run on PCs and compatibles with EGA or better graphics capabilities. The recommended configuration includes DOS 5.0, a 25-MHz 386 or faster processor, and a math coprocessor. A $500-\mathrm{kB}$ partition is sufficient to run most of the modules, but several require $540 \mathrm{kB}$. The modules were written using the Quest Authoring System [6], Versions 3.0, 4.0, and 4.1. The 11 modules and a brief description of them are as follows:

1. CONCENTRATION: A foundation for creative problem solving techniques, patterned on the game Concentration (Fig. 4).

2. EXPLORE: An exercise that leads the students to discover the true cause of a problem. Detective SheerLuck Holmes leads them on an investigation of problems arising at the Light-Bright Flashlight Co. The student then works on the problem of selecting the correct membrane for a heart-lung machine (Fig. 5).

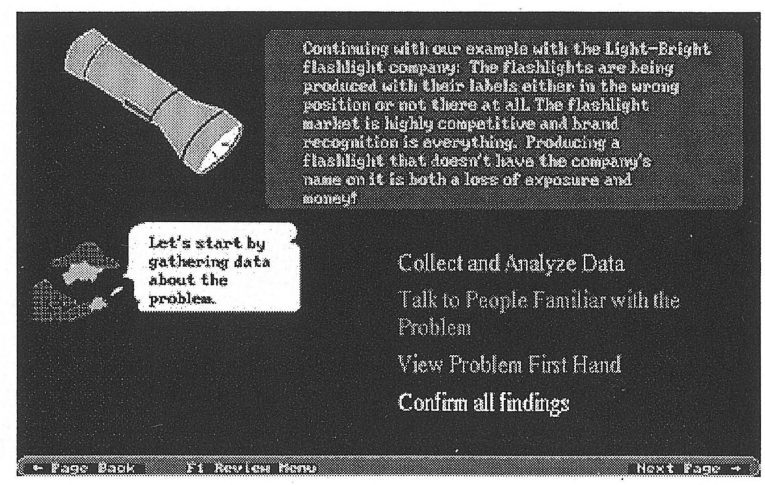

Figure 5 Explore module. 


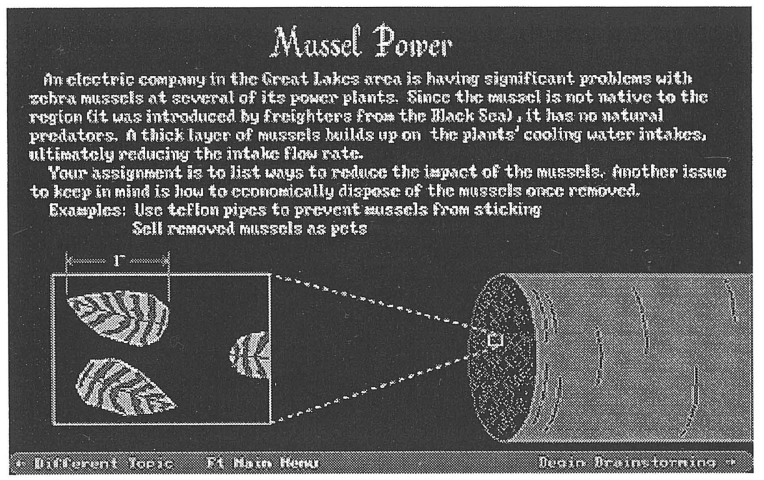

Figure 6 Brainstorming module.

3. DUNCKER: Introduces three techniques to refine the problem statement to converge on the real problem. In the review section of the module, the students investigate the problem of a grocery's freezer doors fogging up. They then solve one of three problem scenarios: "How to drop a tomato," "Unsmashing the smashing serve," and "That is how the chip crumbles."

4. BRAINSTORMING: Helps the student generate original, yet applicable solutions to a specific problem using the brainstorming process (Fig. 6).

5. SITUATION ANALYSIS: Introduces the concept of situation analysis for prioritizing problems. The scenario is based on the explosion of a gas truck that actually happened in a Midwestern town (Fig. 7).

6. PROBLEM ANALYSIS: Presents the four dimensions of problem analysis: identification, location, timing, and magnitude. The student assumes the role of a coatings engineer and must determine why there are paint defects on the cars rolling off the assembly line. During the investigation, the student can actually "speak" to workers involved

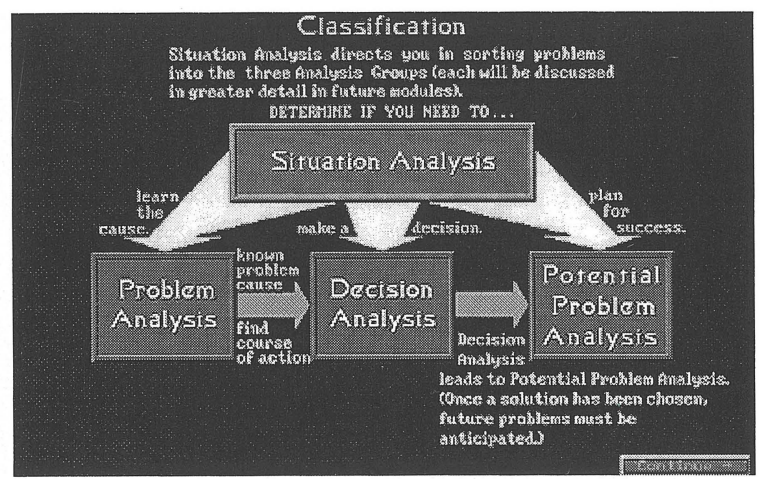

Figure 7 Situation Analysis module.

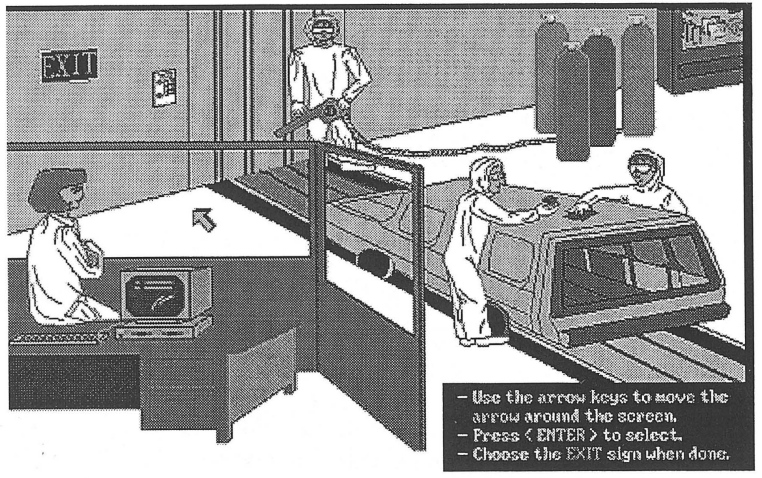

Figure 8 Problem Analysis module.

in the process to gather information. This scenario is based on an actual case history from one of the major auto manufacturers (Figs. 8 and 9).

7. DECISION ANALYSIS: Introduces students to the process of decision making in a rational way. The student assumes the role of a recruiter and must select a job applicant from a pool of candidates based on interviews conducted.

8. POTENTIAL PROBLEM: Helps the student identify potential problems with their solutions before they actually occur. The student is asked to analyze a cross-country solar car road race as an exercise. This scenario is based on the 1993 World Solar Car Race (Fig. 10).

9. PLANNING: Teaches the students how to implement solutions using a Gantt chart, critical path planning, deployment charts, and budgets. The exercise analyzes the construction of a steel bridge for a bridge-building competition.

10. EVALUATION: Stresses the importance of reviewing and evaluation the solution during the course of a project. The near marketing

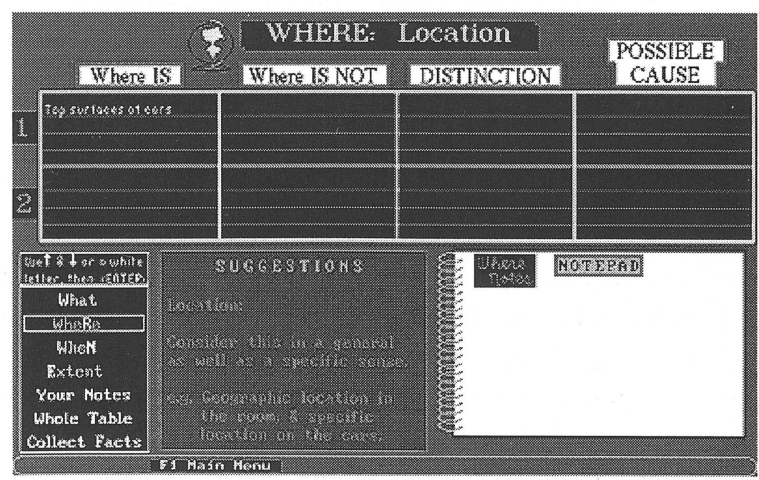

Figure 9 KT table for Problem Analysis. 


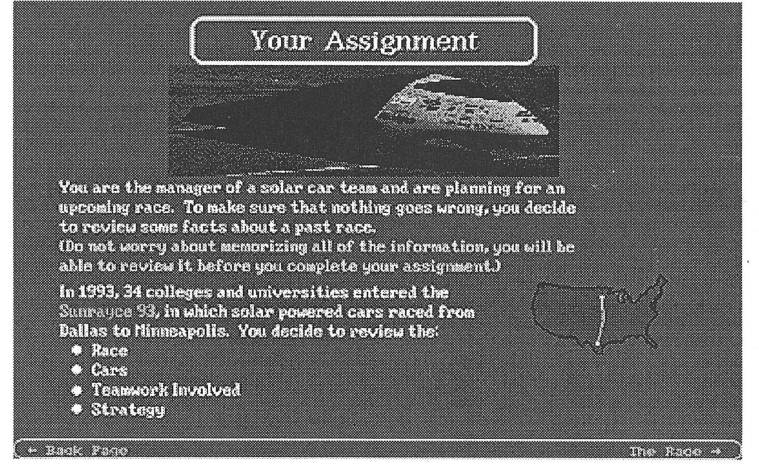

Figure 10 Potential Problem Analysis module.

disaster of New Coke is examined. The student then assumes the role of an employee at a paper mill looking to expand, and must evaluate the proposed solution.

11. ETHICS: This module introduces the concept of ethics. The student is placed in the role of an employee at a chemical plant with some environmental problems, and must make some tough decisions on the necessary course of action for the company.

Flyers were sent to nearly every U.S. college of engineering offering these modules for use by their faculty and students. A total of 131 schools re-

\section{BIOGRAPHIES}

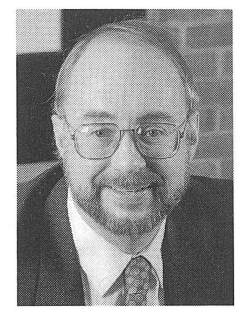

H. Scott Fogler, the Vennema Distinguished Professor of Chemical Engineering at The University of Michigan, has research interests in flow and reaction in porous media, colloid stability, wastewater treatment, and dissolution kinetics in microelectronics fabrication. He is author of over 130 research publications in these areas. In addition, he is author of four books. The Elements of Chemical Reaction Engineering, 2nd edition, published by Prentice Hall in 1992, is the most used book on this subject in the world. His most recent book, Strategies for Creative Problem Solving, coauthored with Steven E. LeBlanc, was published by Prentice Hall in August 1995.

In 1980, Professor Fogler was a first recipient of the newly instituted award for Outstanding Research from the University of Michigan College of Engineering. Also, he received in 1980 the Chemical Engineer of the Year Award from the Detroit sec- quested the modules, which were distributed to them free of charge. The modules are still available to interested academic institutions through the CACHE Corporation: P.O. Box 7939, Austin, TX 78713-7939; Telephone: (512) 471-4933; FAX: (512) 295-4498. More information can be found on the World Wide Web at location: http://www.engin. umich.edu./labs/mel/class/probsolv/pshome/html.

\section{REFERENCES}

[1] H. S. Fogler and S. E. LeBlanc, Strategies for Creative Problem Solving, Prentice Hall, Englewood Cliffs, NJ, 1995.

[2] D. R. Woods, A Strategy for Problem Solving, 3rd Ed., Department of Chemical Engineering, McMaster University, Hamilton, Ontario, 1985.

[3] H. S. Fogler, S. Montgomery, and R. Zipp, "Interactive computer modules for undergraduate chemical engineering instruction,' Comput. Appl. Eng. Educ., Vol. 1, No. 1, 1992, p. 11.

[4] R. Snow and M. Farr, Aptitude, Learning and Instruction. Vol. 3: Cognitive and Affective Process Analysis. Erlbaum, Hillsdale, NJ, 1987.

[5] S. M. Montgomery and H. S. Fogler, "A classification scheme for interactive computer-aided instructional software,' J. Eng. Educ., January 1996.

[6] Quest is a product of Allen Communication, 140 Lakeside Plaza II, 5225 Wiley Post Way, Salt Lake City, UT 84116; telephone: (801) 537-7800. tion of the American Institute of Chemical Engineers. In 1984, he was appointed the Vennema Distinguished Professor of Chemical Engineering. He received the University of Colorado Distinguished Alumnus Award in 1987, and in 1988 he was elected president of the Computer Aids for Chemical Engineering (CACHE) Corporation. In 1993, he received the W. Corcoran Award for Best Paper in Chemical Engineering Education. In 1994, he was elected a director of the American Institute of Chemical Engineers and a fellow of the AIChE, and he was selected as an advisory editor for the Prentice Hall International Series in the Physical and Chemical Engineering Sciences. Also in 1994 he received the Inaugural Adler Lectureship at Case Western Reserve University and was a McCabe Lecturer at North Carolina State University. Most recently, he received in 1995 the AIChE Warren K. Lewis Award.

Steven E. LeBlanc (Biographical sketch and photograph not available.) 